\title{
Health literacy and health outcomes in patients with low back pain: a scoping review
}

Ye King Clarence See ${ }^{1 *} \mathbb{D}$, Helen Elizabeth Smith', Lorainne Tudor Car ${ }^{1}$, Joanne Protheroe?

Wei Cong Wong ${ }^{1}$ and Bernadette Bartlam ${ }^{1,2}$

\begin{abstract}
Background: Low back pain is a leading cause of disability worldwide. Health literacy has been associated with pain intensity and pain control. However, there is a paucity of evidence regarding this association. In the field of low back pain research, inconsistent reporting of outcomes has been highlighted. To address this issue a Core Outcome Set has been developed.
\end{abstract}

Objectives: The objectives of this scoping review were: (1) The health literacy measures currently employed for low back pain and the aspects of health literacy they include. (2) The low back pain health outcomes included in such work. (3) The extent to which these health outcomes reflect the Core Outcome Set for Clinical Trials in Non-Specific Low Back Pain.

Methods: The search included thirteen bibliographic databases, using medical subject heading terms for low back pain and health literacy, and followed the Preferred Reporting Items for Systematic Reviews and Meta-Analyses extension for Scoping Reviews guidelines. The eligibility criteria were defined by the Joanna Briggs Institute PCC mnemonic. A thematic framework approach was used for analysis.

Results: The search yielded ten relevant studies for inclusion, amongst which a total of nine health literacy measures and 50 health outcome measures were used. Most health literacy measures focused on functional health literacy, with few assessing communicative and critical health literacy. The health outcomes assessed by the included studies could be broadly categorised into: Pain, Disability, Behaviour, Knowledge and Beliefs, and Resource Utilisation. Most of these outcome measures studied (36 out of 50) did not directly reflect the Core Outcome Set for Clinical Trials in NonSpecific Low Back Pain.

Conclusions: To allow for comparison across findings and the development of a rigorous evidence base, future work should include the Core Outcome Set for Clinical Trials in Non-Specific Low Back Pain. There is an urgent need to broaden the evidence-base to include regions where low back pain morbidity is high, but data is lacking. Such work demands the incorporation of comprehensive measures of health literacy that have both generic and culturally sensitive components.

Keywords: Core Outcome Set, Health outcomes, Chronic pain, Disability, Musculoskeletal conditions

${ }^{*}$ Correspondence: clarencesee@gmail.com

${ }^{1}$ Lee Kong Chian School of Medicine, Nanyang Technological University,

Singapore, Singapore

Full list of author information is available at the end of the article

\section{Background}

Low back pain (LBP) is the single leading cause of disability globally and is rising [1,2]. In 2017 , the point prevalence of LBP was estimated to be $7.5 \%$ the global population, or approximately 577 million people [3]. Financial costs from LBP are estimated to be in the order 
of billions of US dollars (USD) [2, 4], while the economic burden of members of the workforce suffering from LBP is estimated in the USA alone to be USD 7.4 billion/ year [5]. Traditionally conceptualised as solely secondary to mechanical injury, LBP is now described within a bio-psychosocial model, resulting from an interaction of physical, psychological and social influences [6]. Risk factors for LBP include an older age, increased psychological or psychosocial stress, a lower socioeconomic status, and a lower educational status $[7,8]$.

Effective self-management is crucial to improving LBP outcomes $[9,10]$. Studies have also demonstrated the need to focus on health literacy (HL) in order to develop effective patient education materials and/or patient resources to support self-management in such patients $[11,12]$. The concept of HL is extensive and incorporates functional, communicative and critical domains [13]. It is defined as "the achievement of a level of knowledge, personal skills and confidence to take action to improve personal and community health by changing personal lifestyles and living conditions" [14]. At its core is an observable set of skills that can be developed and improved through effective communication and education to enhance autonomy and empower people to make decisions relating to their health and changing circumstances $[14,15]$. At the inaugural Outcome Measures in Rheumatology Clinical Trials (OMERACT) Health Literacy Special Interest Group workshop, 16 themes at the micro, meso and macro level were identified, including cognitive capacity, access to information, and health systems [16]. Independent of other socio-demographic factors, low HL is associated with higher mortality amongst older people, poorer health outcomes, and higher morbidity [17-19]. On the other hand, higher HL is linked to lower pain intensity and better pain control among those with chronic pain $[1,20]$.

Despite the need for a stronger evidence base in LBP management, inconsistent reporting of outcomes in clinical trials of patients with LBP has been highlighted [21]. This potentially hinders the comparison of findings across studies and the reliability of systematic reviews. To address this issue a core outcome set (COS) has been developed, led by an International Steering Committee, defining the minimum set of outcomes that should be reported in all clinical trials. The COS includes 'physical functioning,' 'pain intensity', 'health-related quality of life' and 'number of deaths' [22].

There also exists a paucity of research to underpin evidence-based practice of LBP treatment in low- and middle-income countries (LMIC) [23, 24]. This is a substantial knowledge gap given the significance of LBP in LMICs. Asia alone has the largest number of LBP disability-adjusted life years internationally and the highest risk of occupational LBP is in the agricultural sector-a major sector in Asian economies [25]. Existing evidence tends to be from high income countries and cannot be accurately applied to the LMIC context, given that pain reporting, manifestation and management is influenced by socio-cultural and genetic factors [26].

To develop more evidence-based interventions and guidelines we need to better understand the relationship between HL and LBP outcomes. An initial scoping search of the literature was conducted to assess whether reviews and guidelines on this topic have already been published and what was lacking. This only yielded a single systematic review by Edward et al. in 2018 on the impact of HL on LBP management. The study identified only three relevant studies, all of which were based in high income Western nations. However, the authors of the review acknowledged "possible incomplete retrieval of identified research and reporting bias" [27] as the search was limited to four bibliographic databases and limits were also placed on year of publication, language, and article formats, amongst other search filters [27].

This scoping review builds on Edward et al.s work and had three objectives. These were to methodically map evidence on:

1. The health literacy measures currently employed for low back pain and the aspects of health literacy they include.

2. The low back pain health outcomes included in such work.

3. The extent to which these health outcomes reflect the Core Outcome Set for Clinical Trials in Non-Specific Low Back Pain.

Scoping reviews are used instead of systematic reviews where the purpose of the review is to identify knowledge gaps, scope a body of literature, clarify concepts or to investigate research conduct [28]. This methodology was chosen in the light of the paucity of existing literature and to reflect and build from the limitations encountered in the work of Edward et al. [27]. To do so, this scoping study expanded the search from four to 13 bibliographic databases and did not utilise search limiters or filters such as time or language filters. Unlike the systematic review carried out by Edward et al. [27], this study is a scoping review with the emphasis on identifying the variety of HL and LBP outcome measures employed in existing literature, rather than reporting the degree of association between HL and LBP health outcomes. The aim in doing so is to provide a critique on the choice of 
outcomes studied and measures used, and to identify implications for future research.

\section{Materials and methods Literature search strategy}

The searches were conducted in: MEDLINE, Pubmed, Academic Search Complete, The Cumulative Index to Nursing and Allied Health Literature, Education Source, Education Resource Information Centre, PsycINFO, Global Health, Embase (Ovid), Web of Science, Cochrane, Google Scholar, and ClinicalKey.

$\mathrm{MeSH}$ (medical subject heading) terms used included: Back Pain, Back Ache, Back Pain with Radiation, Back Pain without Radiation, Backache, Vertebrogenic Pain Syndrome, Low Back Pain, Low Back Ache, Low Back Pain Mechanical, Low Back Pain Posterior Compartment, Low Back Pain Postural, Low Back Pain Recurrent, Low Backache, Lower Back Pain, Lumbago, Mechanical Low Back Pain, Postural Low Back Pain, Recurrent Low Back Pain.

The MeSH term used to search for HL was Health Literacy. No additional search filters were applied. See "Appendix 1" for an example of a search strategy. The search was conducted in August 2019. It was updated in February 2021, reflecting the peer-review process in the context of COVID-19, and no additional studies were identified as meeting the inclusion criteria.

The search strategy was developed in consultation with the library team at the University, as well as expert opinion within the research team, which consisted of a range of expert researchers and clinicians [29]. This included BB (social sciences, primary care research, musculoskeletal research, patient perspectives and health literacy), HES (primary care clinician, health services research, evidence-based medicine), LTC (primary care clinician, health services research, evidence-based medicine, and systematic reviews) and JP (primary care clinician, musculoskeletal conditions, health services research and health literacy).

\section{Inclusion and exclusion criteria}

The Joanna Briggs Institute (JBI) manual's PCC mnemonic [30] was used to clarify the research focus in formulating the inclusion and exclusion criteria (Table 1):

- Population-Patients with LBP ( $\geq 10 \%$ of study population), of any age, gender, or race

- Concept-Relationship of LBP health outcomes to HL

- Context-Any healthcare setting, in any geographical setting

Only research studies were included in this scoping review as the objectives of this study focused on measures used in LBP research. Hence other sources of evidence (e.g. grey literature, policy documents, expert opinions, guidelines) were not included. In addition, studies for inclusion required the use of specific HL and health outcome measures. Studies were excluded if they only analysed generic literacy, numeracy, and education level not in the context of healthcare. Generic patient education interventions have the potential to influence non-HL related determinants of LBP, hence drawing conclusions about HL's effects on LBP from these studies may be inaccurate [31], and for this reason these studies were excluded.

\section{Study selection, data extraction and analysis}

The search strategy followed the Preferred Reporting Items for Systematic Reviews and Meta-Analyses extension for Scoping Reviews (PRISMA-ScR) guidelines [32]. An independent review of titles and abstracts from the initial search was conducted by two reviewers (CS and WWC). Any discrepancies were resolved through discussion between reviewers, with a third reviewer (HES) included when necessary. However, no discrepancies which could not be resolved between reviewers were encountered. Studies then underwent a full-text review if they investigated a relationship between HL and LBP outcomes.

Data extraction included determinants of HL (age, gender, race, and education level) [33], study design, and

Table 1 Inclusion and exclusion criteria

\begin{tabular}{ll}
\hline Inclusion criteria & Exclusion criteria \\
\hline $\begin{array}{l}\text { Patients with LBP ( } \geq 10 \% \text { of study population), of any age, } \\
\text { gender, or race }\end{array}$ & $\begin{array}{c}\text { Non-research or Non-peer reviewed sources of evidence (e.g. grey literature, policy docu- } \\
\text { ments, expert opinions, guidelines) } \\
\text { Any healthcare setting, in any geographical setting }\end{array}$ \\
$\begin{array}{c}\text { Studies only analysing generic literacy, numeracy, and education level not in the context } \\
\text { of healthcare }\end{array}$ \\
$\begin{array}{l}\text { Any peer reviewed research study (of any study design) } \\
\text { Utilisation of specific HL and LBP health outcome measures }\end{array}$ \\
\hline
\end{tabular}


types of measures used. Thematic analysis as advocated by Levac et al. [34] was done by adopting a framework analysis approach $[35,36]$. The health outcomes used were collated and coded into descriptive themes, and then grouped into overarching categories. These categories were then mapped against the Core Outcome Set for Clinical Trials in Non-Specific Low Back Pain [22], namely 'physical functioning,' 'pain intensity', 'healthrelated quality of life' and 'number of deaths'. The HL measures used were categorised according to their validated component of $\mathrm{HL}$, or if absent, the intention of that specific study. This was done using the classification proposed by Nutbeam, namely functional, communicative and critical HL $[37,38]$. The components of this classification have a graded order of complexity, functional HL being the most basic, and critical HL being the most advanced [37]. Functional HL encompasses basic skills in reading and writing, which are important for instance in understanding prescriptions or medicine labels. Communicative HL includes social skills and advanced cognitive and literacy skills to actively participate in daily activities. It is important for example in building up rapport with a social support group. It is also crucial in the doctorpatient relationship, as evidenced by HL tools such as Teach Back aiming to facilitate this [39]. Critical HL comprises the use of even more advanced cognitive and social skills to exert great control over life events and situations. An example of operationalising critical HL is organising social advocacy health promotion within communities, to enable and empower individuals to 'judge, sift and use' health information in the context of their own lives and social worlds [40].

As this was a scoping review, grading of evidence was not conducted. Instead, this study followed the Preferred Reporting Items for Systematic Reviews and Meta-Analyses extension for Scoping Reviews (PRISMA-ScR) guidelines [32], as detailed in "Appendix 2".

\section{Results}

\section{Articles reviewed}

The initial search yielded 5509 articles. After removing duplicates and reviewing titles and abstracts, 18 articles remained for full-text review. Ten of these were included in the final analysis (Fig. 1). The key excluded sources with rationale for their exclusion are listed in "Appendix 3". Both 2010 and 2011 papers by Briggs et al. [10, 41] were included and recorded as separate studies, as each publication studied different HL measures.

\section{Summary of key data retrieved from full text reviews}

Despite no restrictions being placed on the year of publication, all studies meeting the inclusion criteria were published in 2010 or later, and were all cross-sectional in design (Table 2). They utilised structured questionnaires, apart from one mixed methods study which also used interviews. In terms of country of origin, two studies were conducted in Australia, four in the United States of America, three European studies across four centres (Germany, Austria, Switzerland and Italy), one in Saudi Arabia. Five of the cross-sectional studies solely studied patients with LBP, while the other five studies included LBP as a significant portion of their patient population $(>10 \%)$, one of which provided a subpopulation analysis of patients with LBP.

All ten studies focused on adult populations ( $\geq 18$ years) and had a majority female population, with one study having entirely female participants. Racial break-down was only provided by two USA studies, both of which had predominantly white study populations. Nine studies collected data on education level, most reporting an even spread across participants.

\section{Summary of HL measures used}

Nine different HL measures were used across the ten studies (Table 3). Most HL measures assessed functional $\mathrm{HL}$, while the number that evaluated communicative and critical HL were fewer than half (Table 4).

In their 2010 paper, Briggs et al. [10] used the Shortform Test of Functional Health Literacy in Adults (S-TOFHLA), which comprises of two prose passages and four items testing numeracy. It is a validated assessment of functional HL with good internal reliabilityCronbach's alpha 0.68 for the 4 numeracy items [42] and 0.97 for the reading comprehension items [13, 42, 43]. Spearman's correlation coefficient between the S-TOFHLA and the Rapid Estimate of Adult Literacy in Medicine (REALM) was 0.80 [42]. Briggs et al. [10] also used telephone interviews to assess HL by asking participants on how they sought, understood and utilised LBP information.

Subsequently in their 2011 paper, Briggs et al. used the Health Literacy Measurement Scale (HeLMS) [41], a psychometrically tested tool with good internal consistency (Cronbach's alpha $>0.82$ ), and validity (confirmatory factor analysis showing good fit for seven domains and moderate fit for one) [44]. It goes beyond functional HL to include communication skills, computation skills, and social support, thereby overcoming limitations of the S-TOFHLA [41, 45, 46]. The HeLMS sets out to assess "overall capacity to seek, understand and use health information within the healthcare setting" by asking questions such as "Are you able to see a doctor when you need to?" [41]. By doing so it attempts to assess all three 


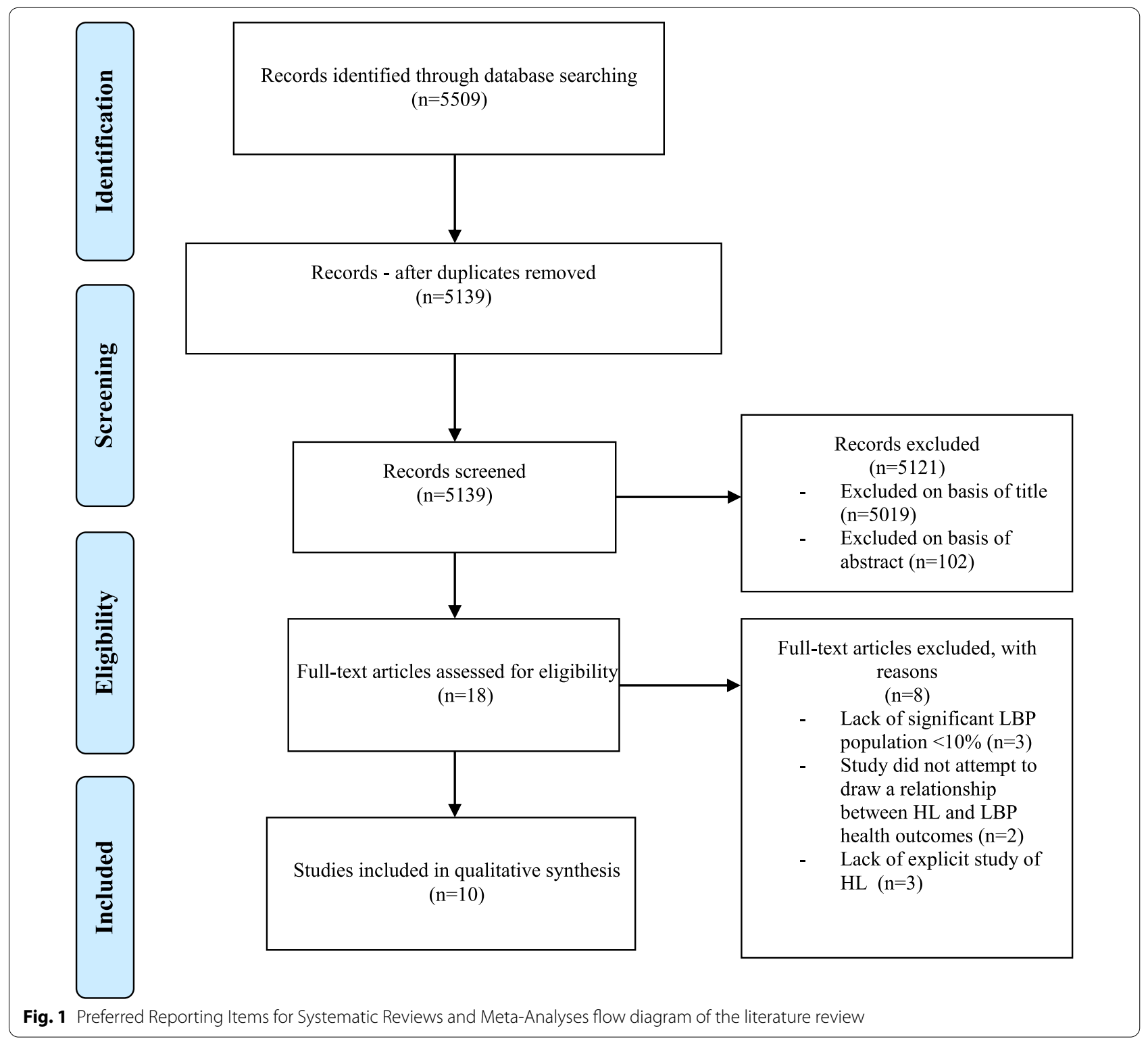

domains of health literacy: functional, communicative, and critical.

The Newest Vital Sign (NVS) was the most frequently used HL measure (Table 3), utilised by Devraj, Herndon and Griffin, Al-Eisa, Buragadda and Melam, and Glassman et al. [12, 47, 48]. The NVS is convenient to use and has a sensitivity equivalent to the TOFHLA for identifying inadequate $\mathrm{HL}-$ with an area under the $\mathrm{ROC}$ curve (AUROC) of 0.88 , using the TOFHLA as the gold standard [42]. It is reported to have a Cronbach's alpha of $0.76[42,49]$, and is a widely used assessment of functional HL, with six questions regarding a standardised ice cream nutrition label [50].
Farin, Ullrich and Nagl developed the HELP questionnaire (Health Education Literacy of Patients with chronic musculoskeletal diseases), an 18-item assessment that aims to summarise a patient's reported communication and comprehension difficulties in health education and treatment [11]. The questions were classified as "comprehension of medical information" (assessing functional $\mathrm{HL}$ ), "communicative competence in provider interactions" (assessing communicative HL), and "applying medical information" (assessing critical HL). Questions such as "How much difficulty did you have communicating your own expectations and wishes in terms of your therapy?" were scored on Likert scales anchored from 


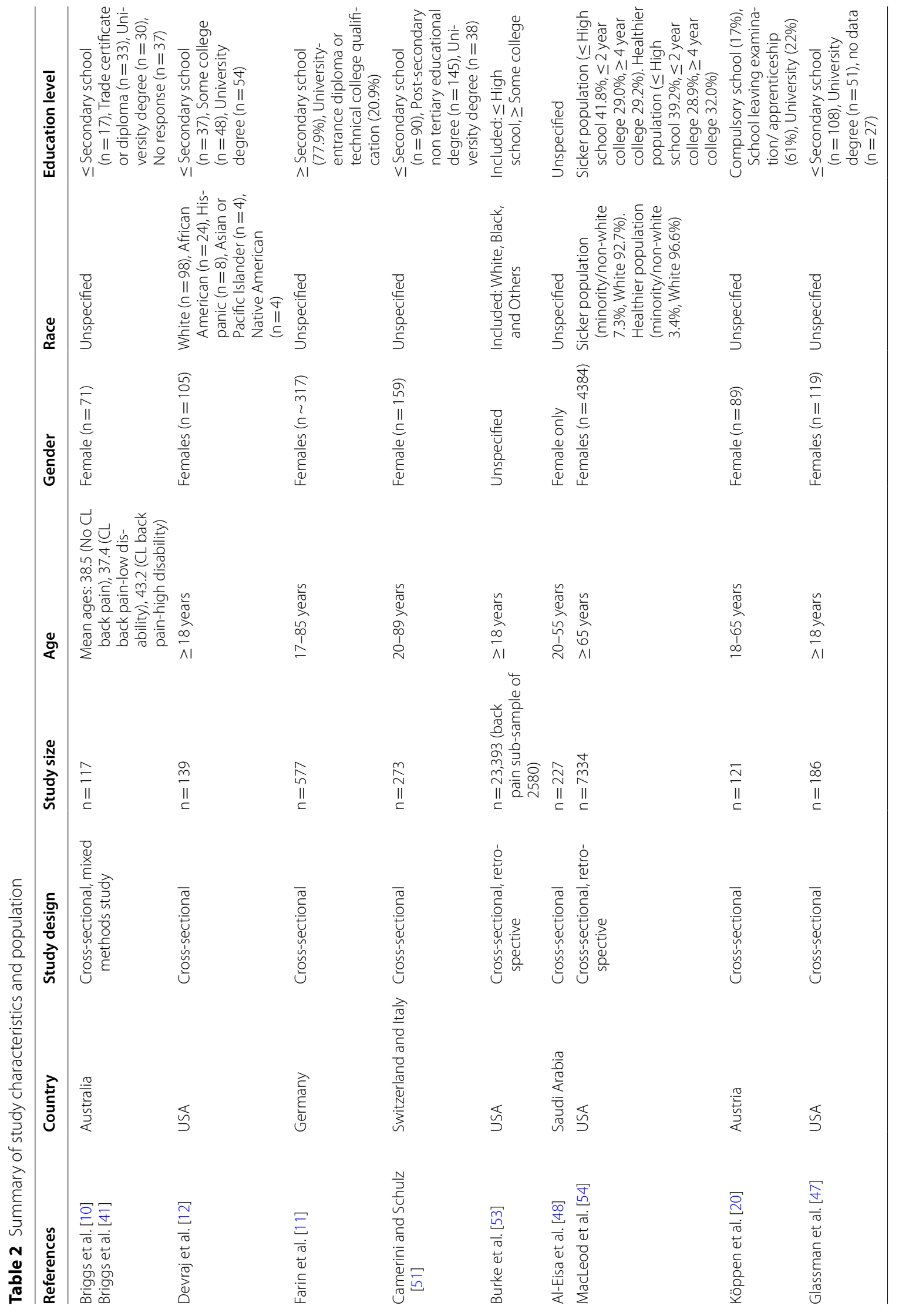




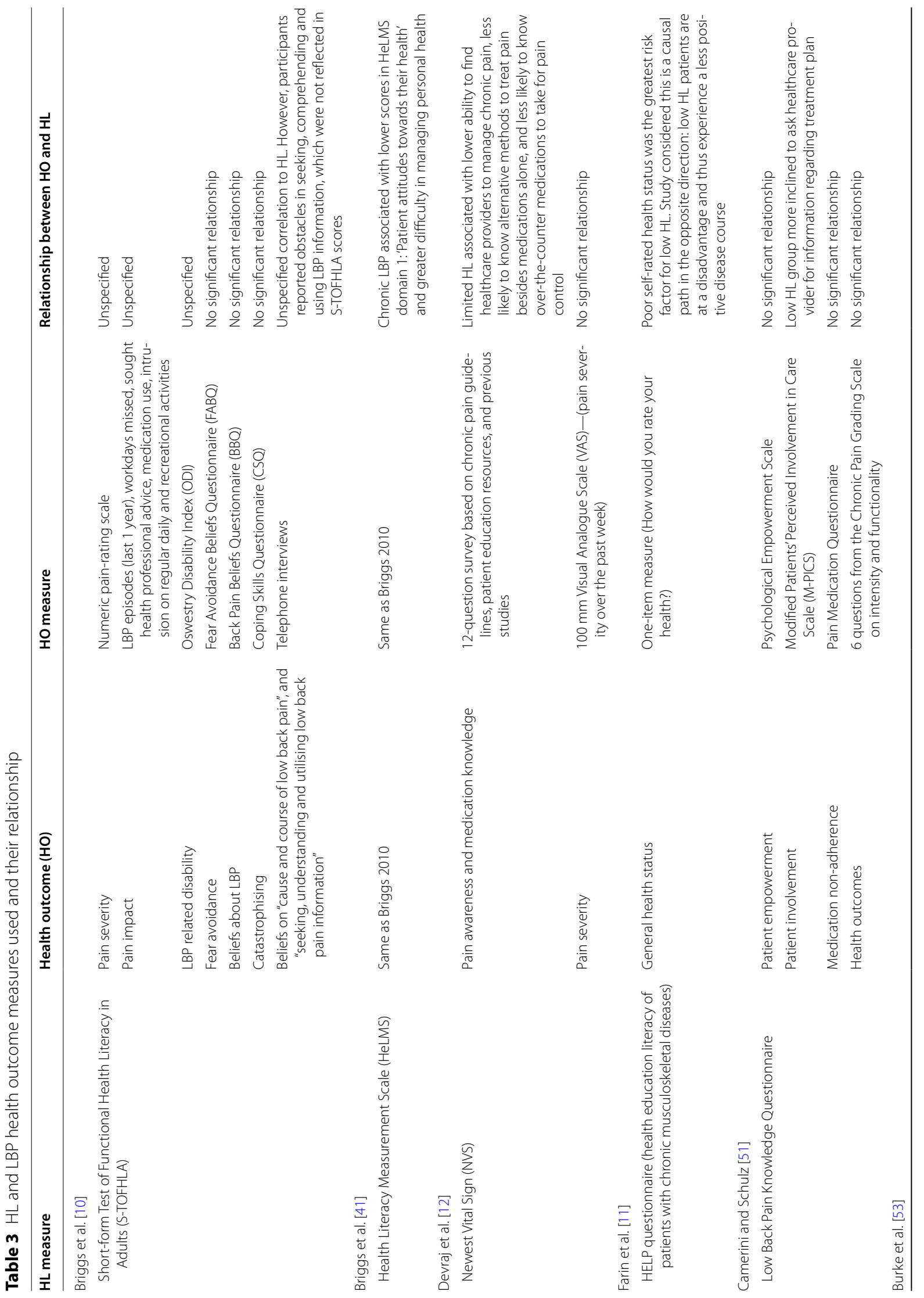




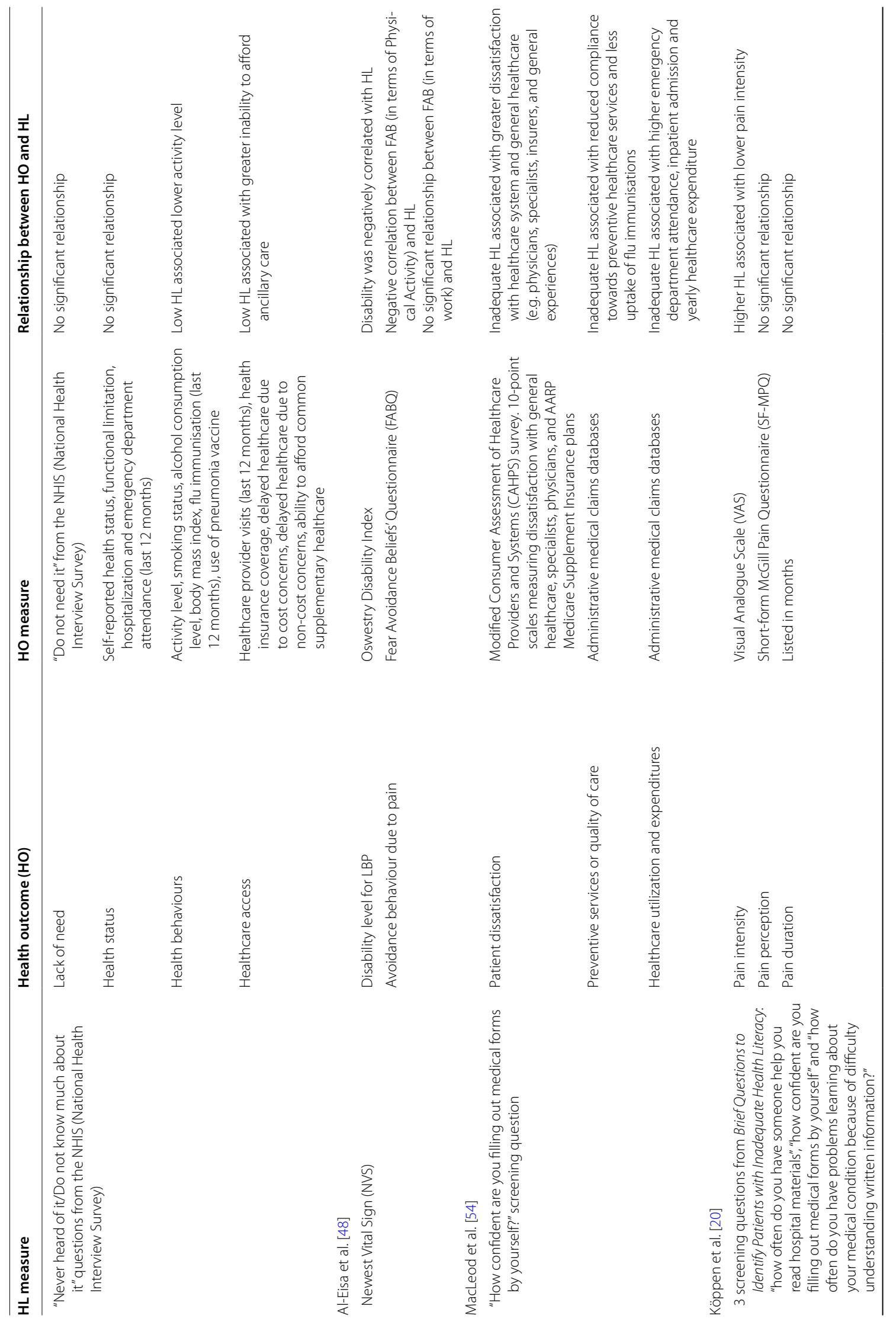




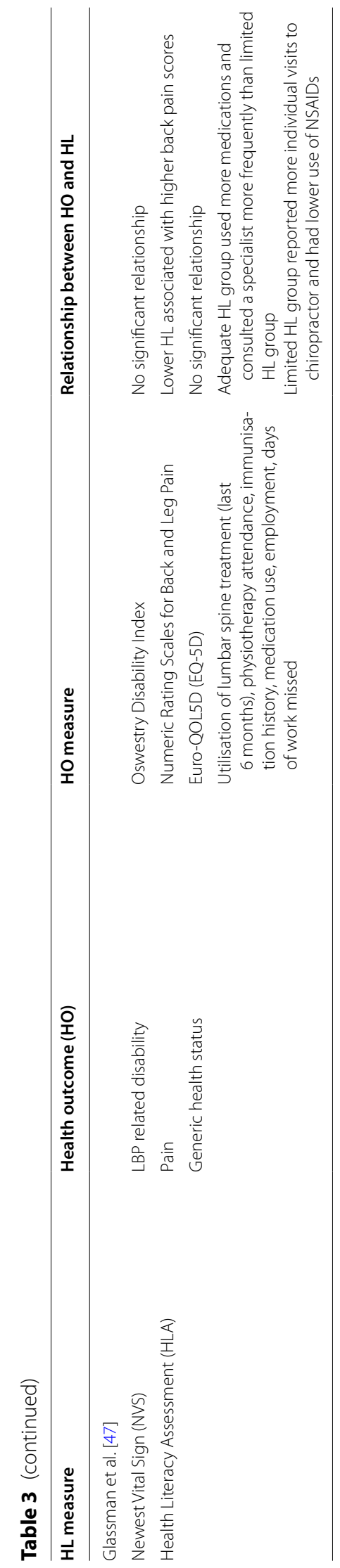


Table $4 \mathrm{HL}$ measures used and the components of HL they cover

\begin{tabular}{|c|c|c|c|}
\hline HL measure & Functional HL & Communicative HL & Critical HL \\
\hline Short-form Test of Functional Health Literacy in Adults (S-TOFHLA) & YES & NO & NO \\
\hline Health Literacy Measurement Scale (HeLMS) & YES & YES & YES \\
\hline Low Back Pain Knowledge Questionnaire & YES & NO & NO \\
\hline Newest Vital Sign (NVS) & YES $\times 3$ & NO & NO \\
\hline Health Literacy Assessment (HLA) & YES & NO & NO \\
\hline "How confident are you filling out medical forms by yourself?" screening question & YES & NO & NO \\
\hline $\begin{array}{l}\text { "Never heard of it/Do not know much about it" questions from the NHIS (National Health Interview } \\
\text { Survey) }\end{array}$ & YES & NO & NO \\
\hline HELP questionnaire (health education literacy of patients with chronic musculoskeletal diseases) & YES & YES & YES \\
\hline 3 screening questions from Brief Questions to Identify Patients with Inadequate Health Literacy & YES & NO & NO \\
\hline Number of studies—HL component assessed (\%) & $11(73.3 \%)$ & $2(13.3 \%)$ & $2(13.3 \%)$ \\
\hline
\end{tabular}

1 to 5 , with lower values indicating a higher HL. The resulting questionnaire's psychometric properties were deemed to be good (Cronbach's alpha 0.88 to 0.95 , unidimensionality and Rasch model fit established) [11].

Camerini and Schulz [51] interpreted HL based on scores from the Low Back Pain Knowledge Questionnaire (LKQ). The Questionnaire involved multiplechoice questions on topics such as the aetiology and management of LBP. Although the LKQ did not set out to be a direct measure of HL, its focus was on declarative and procedural knowledge which Camerini and Schulz argued to be acquired using functional HL [51]. Hence the LKQ was used as a surrogate measure of functional HL. The LKQ was assessed with both intraobserver and inter-observer reproducibility (Spearman's correlation coefficient and intra-class correlation coefficient ranging from 0.61 to 0.95 ) and internal consistency (Cronbach's alpha ranging from 0.71 to 0.77 ) [52].

Measurement of functional HL alone is also seen in other studies. Burke, Nahin and Stussman used the response option "Never heard of it/Do not know much about it" from the National Health Interview Survey, arguing that this serves as an indicator of health knowledge which in turn is a correlate of functional HL [53]. MacLeod et al. used a validated single-item screener "How confident are you filling out medical forms by yourself?" as a measure of functional HL [54]. This had an AUROC of 0.82 for detecting limited HL, and 0.79 for detecting limited or marginal HL, when referenced against the REALM functional HL measure [55].

Köppen et al. used HL questions taken from the Brief Questions to Identify Patients with Inadequate Health Literacy [20], a screening tool for functional HL validated against the S-TOFHLA [56]. These included the questions "how often do you have someone help you read hospital materials" (AUROC 0.87), "how confident are you filling out medical forms by yourself" (AUROC 0.80) and "how often do you have problems learning about your medical condition because of difficulty understanding written information?" (AUROC 0.76) $[20,56]$.

In addition to the NVS mentioned above, Glassman et al. also used The Health Literacy Assessment, a 10-item self-administered questionnaire using items selected from the computerized Health LiTT measure [47]. The Health Literacy Assessment (Health LiTT) is a validated tool for functional HL that reportedly meets or exceeds psychometric standards, with good reliability (Cronbach's alpha 0.83-0.91) and good evidence for unidimensionality (correlation of $0.90-0.95$ on confirmatory factor analysis) [57]. It assesses HL via three sections: Prose, Document and Quantitative [57]. The Prose section asks participants to fill in missing words in a cloze test passage, while the Document section consists of multiplechoice questions regarding images such as a prescription label. The Quantitative section also uses multiple-choice questions requiring arithmetic computation.

\section{Summary of LBP outcomes retrieved from included studies} $\mathrm{HL}$ was associated with a wide range of outcomes (Table 5). Five overarching categories summarising the studied LBP health outcomes were identified via framework method analysis $[35,36]$ :

- Pain

- Disability

- Behaviour

- Knowledge and Beliefs

- Resource Utilisation 
Table 5 Health outcome measures used by category

\begin{tabular}{|c|c|c|c|c|}
\hline Pain & Disability & Behaviour & Knowledge and beliefs & Resource utilisation \\
\hline \multicolumn{5}{|c|}{ Health outcome measures employed (number of times) } \\
\hline Numerical rating scale (3) & Oswestry Disability Index (4) & $\begin{array}{l}\text { Coping Skills Questionnaire } \\
(2)\end{array}$ & $\begin{array}{l}\text { Back Pain Beliefs Question- } \\
\text { naire (2) }\end{array}$ & Utilisation of medications (3) \\
\hline Visual Analogue scale (2) & Euro-QOL5D (1) & $\begin{array}{l}\text { Fear Avoidance Beliefs Ques- } \\
\text { tionnaire ( } 3 \text { ) }\end{array}$ & $\begin{array}{l}\text { Modified Consumer } \\
\text { Assessment of Healthcare } \\
\text { Providers and Systems } \\
\text { survey (1) }\end{array}$ & $\begin{array}{l}\text { Utilisation of healthcare } \\
\text { appointments (9) }\end{array}$ \\
\hline $\begin{array}{l}6 \text { item Chronic Pain Grad- } \\
\text { ing Scale (1) }\end{array}$ & $\begin{array}{l}6 \text { item Chronic Pain Grading } \\
\text { Scale (1) }\end{array}$ & $\begin{array}{l}\text { Psychological Empower- } \\
\text { ment Scale (1) }\end{array}$ & $\begin{array}{l}\text { One-item measure-How } \\
\text { would you rate your } \\
\text { health? (1) }\end{array}$ & $\begin{array}{l}\text { Healthcare cost_-expendi- } \\
\text { ture/workdays missed/ } \\
\text { affordability (6) }\end{array}$ \\
\hline $\begin{array}{l}\text { Short-form McGill Pain } \\
\text { Questionnaire (1) }\end{array}$ & & $\begin{array}{l}\text { Modified Patients' Perceived } \\
\text { Involvement in Care Scale } \\
\text { (1) }\end{array}$ & & \\
\hline \multicolumn{5}{|l|}{ Pain duration in months (1) } \\
\hline \multicolumn{5}{|l|}{$\begin{array}{l}\text { Oswestry Disability Index } \\
\text { (4) }\end{array}$} \\
\hline \multicolumn{5}{|l|}{ Euro-QOL5D (1) } \\
\hline Others $^{*}(2)$ & Others $^{*}(2)$ & Others $^{*}(1)$ & Others* $(3)$ & \\
\hline * LBP episodes in last 1 year & $\begin{array}{l}\text { *Pain impact (intrusion on } \\
\text { regular daily and recrea- } \\
\text { tional activities) }\end{array}$ & $\begin{array}{l}\text { *Health Behaviours (Activity } \\
\text { level, smoking status, } \\
\text { alcohol consumption } \\
\text { level, body mass index, } \\
\text { flu immunisation in last } \\
12 \text { months, use of pneu- } \\
\text { monia vaccine) }\end{array}$ & $\begin{array}{l}\text { *Telephone interviews (2), } \\
\text { and } 12 \text {-item survey devel- } \\
\text { oped by authors (1) }\end{array}$ & \\
\hline
\end{tabular}

\section{Pain}

Seven studies involved data on pain $[10,12,20,41,47$, $48,51]$, using eight different measures (Table 5). Pain intensity was the most frequently measured aspect, with three studies (Briggs et al., Briggs et al., Glassman et al.) using the Numerical Rating Scale and two (Devraj, Herndon and Griffin, Köppen et al.) using the Visual Analogue Scale (Table 5). Pain intensity was also quantified as a sub-component of the Chronic Pain Grading [51], the Short-form McGill Pain Questionnaire [20], the Oswestry Disability Index (ODI) [10, 41, 47, 48], and the Euro-QOL5D [47]. In addition, the Short-form McGill Pain Questionnaire assesses the nature of pain [58], while other studies looked at pain duration and frequency [10, 20].

\section{Disability}

Five studies involved data on disability [10, 41, 47, 48, 51]. Four studies (Briggs et al., Briggs et al., Glassman et al., Al-Eisa, Buragadda and Melam) used the ODI, a spinal disorder-specific measure of disability which quantifies the difficulty faced in areas such as personal care, movements (e.g. lifting, walking, sitting), and lifestyle (e.g. sex life, travel) [59]. Additionally, Glassman et al. [47] used the Euro-QOL5D (EQ-5D) which, in addition to mobility, self-care and activities of daily living, also screens for anxiety and depression. Both of Briggs et al.s studies [10, 41] supplemented the ODI with an assessment of disability by asking participants on the amount of intrusion one faces in daily and recreational activities. Lastly, the Chronic Pain Grading Scale also asks about functionality using questions such as "In the past 3 months, how much has this pain interfered with your daily activities (e.g. getting dressed, doing shopping)" [51].

\section{Behaviour}

Five studies collected data on patient behaviours [10, $41,48,51,53$ ], involving five forms of health outcome measures (Table 5). The Fear Avoidance Beliefs Questionnaire was most commonly used [10, 41, 48], and asks participants how much they think areas of physical activity and work would affect their LBP [60]. Briggs et al. [10, 41] assessed pain catastrophizing with the Coping Skills Questionnaire. Camerini and Schulz [51] assessed patient empowerment and involvement with two scales, the Psychological Empowerment Scale and Modified Patients' Perceived Involvement in Care Scale respectively. Burke, Nahin and Stussman [53] studied the association between HL and health behaviours such as physical activity level and smoking status. 


\section{Knowledge and beliefs}

Four studies gathered data on patient knowledge and beliefs [15-17, 25], utilising five different health outcome measures. Briggs et al. [10, 41] used the Back Pain Beliefs Questionnaire, which consists of 14 questions exploring beliefs regarding issues such as the management and prognosis of back trouble [61]. They also conducted telephone interviews to understand participant's beliefs regarding the aetiology and course of their LBP. MacLeod et al. [54] used the Modified Consumer Assessment of Healthcare Providers and Systems survey to assess patient dissatisfaction in areas such as general healthcare and doctors. Farin, Ullrich and Nagl [11] used a singleitem measure-"How would you rate your health?" to evaluate participant beliefs on their health status. Finally, Devraj, Herndon and Griffin [12] developed a 12-item survey based on pre-existing pain guidelines and literature to assess the pain awareness and medication knowledge of their participants.

\section{Resource utilisation}

Four studies involved data on resource utilisation [47, $51,53,54]$. A wide variety of resources were studied, and we broadly grouped these outcomes (Table 5) into utilisation of medications, utilisation of healthcare appointments (e.g. lumbar spine treatment, physiotherapy), and healthcare costs (e.g. expenditure, workdays missed). Of these, utilisation of healthcare appointments was measured the most-in nine occasions, while healthcare costs were measured six times, and utilisation of medications was measured thrice (Table 5).

\section{Comparison of included LBP health outcomes against the $\operatorname{COS}$ for clinical trials in non-specific LBP}

A total of 50 health outcome measures were utilised across the ten studies reviewed. Of these, 14 (28\%) were deemed to be directly related to those in the COS but were limited to two outcomes "pain intensity' and "physical functioning" [22] (Table 6). The Pain Numerical

Table 6 Summary of number of health outcome measures directly and indirectly related to the COS for clinical trials in nonspecific low back pain

\begin{tabular}{lll}
\hline COS & $\begin{array}{l}\text { Directly related } \\
\text { outcomes }\end{array}$ & $\begin{array}{l}\text { Indirectly } \\
\text { related } \\
\text { outcomes }\end{array}$ \\
\hline Pain intensity & 6 & 3 \\
Physical functioning & 8 & 0 \\
Health-related quality of life & 0 & 33 \\
Number of deaths & 0 & 0 \\
Totals (\%) & $14(28 \%)$ & $36(72 \%)$ \\
\hline
\end{tabular}

Rating Scale, Pain Visual Analogue Scale, and Shortform McGill Pain Questionnaire directly addressed the core outcome of "pain intensity", while the ODI, Euro-QOL5D, Chronic Pain Grading Scale, and questions on intrusion of daily and recreational activities $[10,41]$ directly addressed the outcome "physical functioning". Measures on pain duration and frequency were only indirectly related to the COS. The COS outcome "health-related quality of life" had the greatest number of measures indirectly addressing it (Table 6). This was because three of the five overarching categories of health outcomes (behaviour, knowledge and beliefs, and resource utilisation) were found to be assessments of the "impact on physical, psychological and social domains of health"-i.e. the COS' definition of "health-related quality of life" [22]. The COS outcome "Number of Deaths" was not explored in any of the included studies.

\section{Association between HL and LBP health outcomes}

Although not a primary aim of this scoping review, we briefly detail here findings on the association between HL and LBP health outcomes as a snapshot of existing literature (Table 3). Out of six studies analysing the relation between HL and levels of pain and disability [10, $12,20,41,47,48]$, only two found a significant association, particularly in the area of pain intensity [20,47]. On behavioural impact, HL had no significant associations with fear avoidance $[10,41]$, pain catastrophising [10, 41], and psychological empowerment [51]. However, patients with low HL scores were found to have a less active lifestyle [53]. Considering patient knowledge and beliefs, those with lower HL scores had more difficulty identifying types and sources of treatment for LBP [12] and were more dissatisfied with their care [54]. However, no significant association was found between HL and beliefs about one's future with LBP [10, 41]. Regarding resource utilisation, it appears that low HL scores were associated with higher utilisation of curative or symptomatic treatment (e.g. emergency room visits), and lower utilisation of preventive medicine (e.g. flu vaccinations) [54].

\section{Discussion}

We will now discuss our results in the context of the three objectives and the implications for evidence and future research i.e. (1) The health literacy measures currently employed for low back pain and the aspects of health literacy they include; (2) The low back pain health outcomes included in such work; (3) The extent to which these health outcomes reflect the Core Outcome Set for Clinical Trials in Non-Specific Low Back Pain.

The scoping review yielded ten relevant studies. Among the nine different measures of HL used, all involved the study of functional HL. The 50 measures of LBP health 
outcomes could be grouped into five thematic categories, namely: Pain, Disability, Behaviour, Knowledge and Beliefs, and Resource Utilisation. However, most of these health outcomes did not seek to directly satisfy the COS for Clinical Trials in Non-Specific LBP.

\section{Health literacy measures employed}

The studies included in this scoping review adopted a wide variety of measures to document HL (nine measures used) and health outcomes (50 measures used). This hampered the comparison of results across studies and the development of a comprehensive evidence-base despite the development of the COS [22].

Despite expanding the search and using a more open search criteria, this study only included seven studies in addition to those in the systematic review by Edward et al. [27]. The dearth of relevant studies in this scoping review highlights the continuing lack of evidence of the relationship between HL and LBP health outcomes.

Although no restrictions were placed on the year of publication, all relevant studies were published in 2010 or later, suggesting that interest in the association between $\mathrm{HL}$ and LBP is relatively recent. This may reflect HL being a relatively new concept within healthcare [62], and the growing interest in LBP as it contributes to rapidly rising healthcare expenditure $[2,63]$. For instance, from 1996 through 2013, US expenditure on low back and neck pain rose by an estimated USD 57.2 billion, becoming the third-highest healthcare spending on a single condition in 2013 [63].

Despite no language or country restrictions being placed on the search, all studies were conducted in high income countries-as defined by the 2021 World Bank classification of economies [64]. This may be a barometer of societal readiness to integrate HL into LBP management. Most pressingly, there is a notable absence of research attempting to draw associations between LBP and HL in LMICs and collectively in Asia, Africa, and South America. This is in keeping with previous epidemiological studies remarking that LBP monitoring and research is largely restricted to high income countries, while being under-researched in LMICs [23, 24]. Alongside this is an increasing recognition of the need to develop and use culturally sensitive HL tools [65].

\section{Outcome measures used}

Few studies incorporated the four outcome domains of the COS (pain intensity, physical functioning, health related quality of life, and number of deaths); only 14 of the 50 health outcome measures used did so. Moreover, these 14 measures were limited to the two core outcome domains of pain intensity and physical functioning (Table 5). This suggests a divergence of opinions on what is deemed as a key health outcome for people with LBP. This is concerning given that development of the COS incorporated a comprehensive range of views via a Delphi process with patients, care providers and researchers, a review by panellists who had published extensively on LBP, and by a four-continent International Steering Committee [22].

Given the methodology in developing the COS, future studies on LBP are strongly recommended to adopt them. The benefit of adopting the COS is twofold. Firstly, it allows future studies on LBP to have a more robust foundation to build upon. Secondly, the use of common health outcomes allows secondary research to have more compatible data for the comparison of findings. Overall, this allows for the development of a more rigorous evidence base. Also of note, the authors of the COS have subsequently argued for the inclusion of the 24-item Roland-Morris Disability Questionnaire for measuring physical functioning, and the Short Form Health Survey 12 and 10-item PROMIS Global Health form for measuring health-related quality of life [66]. However, none of these tools were used in the included studies (Table 2).

\section{Implications for future research}

As highlighted in our findings, several limitations were noted in the literature with implications for future research design, specifically regarding study design, measures used and included study populations. It is of utmost importance that future research takes these findings into account in curbing the limitations of future research.

By solely employing cross-sectional study designs, the longitudinal relationship between HL and LBP outcomes was not explored. There was also a lack of evidence regarding the efficacy and implementation of $\mathrm{HL}$ interventions for people with LBP. Although a mixed-methods approach is preferable to holistically evaluate the complex construct of HL [67], only the 2010 study by Briggs et al. utilised quantitative and qualitative approaches [10].

Another limitation of in terms of study design was that the primary studies relied heavily on patient reported outcome measures (PROMs), which may be biased by one's physical and psychological states, along with one's memory, willingness, and ability to answer the questions. This may influence one's ability to give accurate selfassessments of health status [68]. This limitation could be overcome by the concurrent use of objective markers (e.g. functional tests), diagnostic imaging (e.g. functional magnetic resonance imaging), and/or observer reported outcomes [69, 70].

Many studies also had limitations in terms of the HL measure used. Communicative and critical HL measures were under-investigated. HeLMS, and the questionnaires 
used by Camerini and Schulz [51], MacLeod et al. [54] and Burke, Nahin and Stussman [53] have not been used as widely as the S-TOFHLA and NVS, and their content validity in other settings requires confirmation. We were also unable to find psychometric data for the HL measure used by Burke, Nahin and Stussman [53]. It is recommended that future works reinforce their HL data by employing the use of HL measures with good psychometric validity and reliability. While a varied questioning style is likely to result in a more complete assessment of $\mathrm{HL}$, measures tended to focus purely on either objective response (e.g. S-TOHHLA and NVS) or subjective replies (e.g. HeLMS). Ideally future studies on HL should use assessment tools that cover all three domains of $\mathrm{HL}$ as well as have vigorous validation in the setting employed.

Study population characteristics were also a source of limitation in the studied literature. Briggs et al. [10, 41] faced a limited distribution of HL, hampering their efforts to analyse the presence of associations between health literacy scores and other outcomes. Studies which excluded patients based on language literacy potentially excluded lower HL participants. If basic language proficiency is required to obtain self-reported patient outcomes, this may come at the cost of excluding certain sectors of the population. The use of translators or pictorial questionnaires need to be explored to enable the inclusion of participants who may be experiencing vulnerability, for example those facing communication barriers or multimorbidity [71, 72].

Responder bias through self-selection was another common limitation in terms of study population design. This is important in the context of HL studies, as low HL patients with lesser ability to communicate well with their healthcare provider may have a tendency to decline study involvement [73]. This limitation may potentially be mitigated using retrospective and anonymised data, rather than depend on the voluntary actions of patients.

\section{Strengths and limitations}

The strengths of this review include the wide search strategy, involving 13 bibliographic databases with no search limiters or filters. By including studies on all forms of LBP health outcomes associated with HL, this review was able to build on the work of Edward et al. [27]. This review also followed best practices in the Joanna Briggs Institute methodology for conducting a scoping review, and the PCC mnemonic was adopted [30]. Expert opinion in LBP, HL, scoping reviews, and literature searching was also consulted. This was in line with best practice recommendations by the Institute of Medicine (US) Committee on Standards for Systematic Reviews of
Comparative Effectiveness Research [74], as well as Arksey and O'Malley's and Levac et al's frameworks for scoping reviews [29, 34].

Nevertheless, the search strategy was not without its flaws. The use of MeSH terms was done with the aim of improving reproducibility of results, especially with searches repeated periodically in this study. However, this ran the risk of missing out on recent articles not yet indexed. Furthermore, a more broadly defined strategy using additional synonyms for $\mathrm{MeSH}$ terms could have broaden the search even more. Grey literature was also excluded, which given the paucity of evidence in the field, could well have enriched this study's findings [75].

The studies by Devraj, Herndon and Griffin [12], MacLeod et al. [54], Farin, Ullrich and Nagl [11], and Köppen et al. [20] did not have a solely LBP population, but were included as the LBP population made up at least $10 \%$ of the overall study. This was pre-determined as the cut-off percentage for eligibility into this review. This cut off has been used as a marker for significance in other studies [76, 77], but caution may be needed when interpreting the results of these studies.

The heterogeneity of measures employed, as well as the paucity of relevant studies, made it difficult to compare findings across studies and provide firm conclusions on the association between HL and each LBP health outcome. Thus, we were unable to draw strong evidencebased conclusions on this. We also note that classifying measurement tools into functional, communicative and critical HL as proposed by Nutbeam [37] is an imperfect method of HL classification, given the wide range of HL definitions employed and the fact that such a classification may not be the intention of the various measures. However, the benefit of using the classification in this review is that it has an ascending level of "difficulty", thus capturing a sense of the complexity and dimensions of HL each measurement tool was seeking to assess, whether implicitly or explicitly.

The protocol was not registered a priori, leading to potential bias. However, as stated, no changes to the protocol were necessitated during the review process and data extraction remained per protocol. Piloting of the data extraction form was also not included. However, these are not requirements of a scoping review and were deemed unnecessary to fulfil the study objectives.

In terms of stakeholder involvement, while experts (clinicians and researchers) in the field of HL and LBP are members of the research team, patients were not consulted. There is growing evidence of the value of patient and public involvement at all stages of the research process [78], and the importance of how best to operationalise this within diverse cultural contexts [79, 80]. While 
deemed to be non-essential at this scoping stage, involving patients in the development of research questions would be essential to further work into the impact of $\mathrm{HL}$ on LBP health outcomes.

\section{Conclusions}

The ten relevant studies included in this review yielded a total of nine different measures of HL and 50 measures of LBP health outcomes. Most health outcomes evaluated by the included studies did not seek to directly satisfy the Core Outcome Set for Clinical Trials in NonSpecific LBP. The wide variety of measures used hampers efforts to form conclusive relationships between HL and LBP outcomes, and precludes the use of a meta-analysis approach. To allow for comparison across findings and the development of a rigorous evidence base, future work should seek to address the Core Outcome Set for Clinical Trials in Non-Specific LBP. Furthermore, research thus far has focused on a narrow range of populations and there is an urgent need to broaden the evidence-base to include those where LBP morbidity is high, but data is lacking. As noted above, this is especially so in LMICs. Such work demands the incorporation of comprehensive measures of health literacy that have both generic and culturally sensitive components.

\section{Appendix 1: Search strategy overviews}

\footnotetext{
Database: Pubmed 1946 to Present.

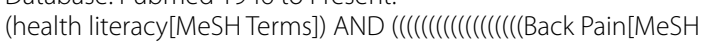

Terms]) OR Back Ache[MeSH Terms]) OR Back Pain with

Radiation[MeSH Terms]) OR Back Pain without Radiation[MeSH

Terms]) OR Backache[MeSH Terms]) OR Vertebrogenic Pain

Syndrome[MeSH Terms]) OR Low Back Pain[MeSH Terms]) OR Low

Back Ache[MeSH Terms]) OR Low Back Pain, Mechanical[MeSH

Terms]) OR Low Back Pain, Posterior Compartment[MeSH Terms])

OR Low Back Pain, Postural[MeSH Terms]) OR Low Back Pain,

Recurrent[MeSH Terms]) OR Low Backache[MeSH Terms]) OR

Lower Back Pain[MeSH Terms]) OR Lumbago[MeSH Terms]) OR

Mechanical Low Back Pain[MeSH Terms]) OR Postural Low Back

Pain[MeSH Terms]) OR Recurrent Low Back Pain[MeSH Terms])

No search filters used (e.g. specifying years, language).

Database: Google Scholar

"Health Literacy" AND ("Back Pain" OR "Back Ache" OR "Back Pain with Radiation" OR "Back Pain without Radiation" OR "Vertebrogenic Pain Syndrome" OR "Low Back Pain" OR "Low Back Ache" OR "Mechanical Low Back Pain" OR "Low Back Pain Posterior Compartment" OR "Postural Low Back Pain" OR "Recurrent Low Back Pain" OR "Low Backache" OR "Lower Back Pain" OR "Lumbago" OR "Mechanical Low Back Pain" OR "Postural Low Back Pain" OR "Recurrent Low Back Pain")

No search filters used (e.g. specifying years, language).

Analysed from page 1 to 520 of the above Google Scholar query.
}

\section{Appendix 2: PRISMA-ScR Checklist (Tricco et al.} [32])

\begin{tabular}{|c|c|c|c|}
\hline Section & Item & $\begin{array}{l}\text { PRISMA-ScR checklist } \\
\text { item }\end{array}$ & Reported on page \# \\
\hline \multicolumn{4}{|l|}{ Title } \\
\hline Title & 1 & $\begin{array}{l}\text { Identify the report as a } \\
\text { scoping review }\end{array}$ & 1 \\
\hline \multicolumn{4}{|l|}{ Abstract } \\
\hline Structured summary & 2 & $\begin{array}{l}\text { Provide a structured } \\
\text { summary includ- } \\
\text { ing, as applicable: } \\
\text { background, } \\
\text { objectives, eligibility } \\
\text { criteria, sources of } \\
\text { evidence, charting } \\
\text { methods, results and } \\
\text { conclusions that } \\
\text { relate to the review } \\
\text { question(s) and } \\
\text { objective(s) }\end{array}$ & $2-3$ \\
\hline \multicolumn{4}{|l|}{ Introduction } \\
\hline Rationale & 3 & $\begin{array}{l}\text { Describe the rationale } \\
\text { for the review in } \\
\text { the context of what } \\
\text { is already known. } \\
\text { Explain why the } \\
\text { review question(s)/ } \\
\text { objective(s) lend } \\
\text { themselves to a } \\
\text { scoping review } \\
\text { approach }\end{array}$ & $4-6$ \\
\hline Objectives & 4 & $\begin{array}{l}\text { Provide an explicit } \\
\text { statement of the } \\
\text { question(s) and } \\
\text { objective(s) being } \\
\text { addressed with } \\
\text { reference to their } \\
\text { key elements (e.g., } \\
\text { population or par- } \\
\text { ticipants, concepts } \\
\text { and context), or } \\
\text { other relevant key } \\
\text { elements used to } \\
\text { conceptualize the } \\
\text { review question(s) } \\
\text { and/or objective(s)) }\end{array}$ & 6 \\
\hline \multicolumn{4}{|l|}{ Methods } \\
\hline $\begin{array}{l}\text { Protocol and registra- } \\
\text { tion }\end{array}$ & 5 & $\begin{array}{l}\text { Indicate if a review } \\
\text { protocol exists, if } \\
\text { and where it can } \\
\text { be accessed (e.g., } \\
\text { web address), and, } \\
\text { if available, provide } \\
\text { registration informa- } \\
\text { tion including regis- } \\
\text { tration number }\end{array}$ & $7-10$ \\
\hline Eligibility criteria & 6 & $\begin{array}{l}\text { Specify the character- } \\
\text { istics of the sources } \\
\text { of evidence (e.g., } \\
\text { years considered, } \\
\text { language, publica- } \\
\text { tion status) used as } \\
\text { criteria for eligibility, } \\
\text { and provide a } \\
\text { rationale }\end{array}$ & 8 \\
\hline
\end{tabular}




\begin{tabular}{|c|c|c|c|c|c|c|c|}
\hline Section & Item & $\begin{array}{l}\text { PRISMA-ScR checklist } \\
\text { item }\end{array}$ & Reported on page \# & Section & Item & $\begin{array}{l}\text { PRISMA-ScR checklist } \\
\text { item }\end{array}$ & Reported on page \# \\
\hline \multirow[t]{2}{*}{ Information sources } & \multirow[t]{2}{*}{7} & \multirow[b]{2}{*}{$\begin{array}{l}\text { Describe all informa- } \\
\text { tion sources (e.g., } \\
\text { databases with dates } \\
\text { of coverage, contact } \\
\text { with authors to } \\
\text { identify additional } \\
\text { sources) in the } \\
\text { search, as well as the } \\
\text { date the most recent } \\
\text { search was executed }\end{array}$} & \multirow[t]{2}{*}{7} & \multicolumn{4}{|l|}{ Results } \\
\hline & & & & $\begin{array}{l}\text { Selection of sources } \\
\text { of evidence }\end{array}$ & 17 & $\begin{array}{l}\text { Give numbers of } \\
\text { sources of evidence } \\
\text { screened, assessed } \\
\text { for eligibility, and } \\
\text { included in the } \\
\text { review, with reasons } \\
\text { for exclusions at } \\
\text { each stage, ideally } \\
\text { using a flow diagram }\end{array}$ & 10 \\
\hline Search & 8 & $\begin{array}{l}\text { Present the full } \\
\text { electronic search } \\
\text { strategy for at least } \\
\text { one database, } \\
\text { including any limits } \\
\text { used, such that it } \\
\text { could be repeated }\end{array}$ & 7 & $\begin{array}{l}\text { Characteristics } \\
\text { of sources of } \\
\text { evidence }\end{array}$ & 18 & $\begin{array}{l}\text { For each source of } \\
\text { evidence, present } \\
\text { characteristics for } \\
\text { which data were } \\
\text { charted and provide } \\
\text { the citations }\end{array}$ & 10 \\
\hline \multirow[t]{2}{*}{$\begin{array}{l}\text { Selection of sources } \\
\text { of evidence }\end{array}$} & \multirow[t]{2}{*}{9} & \multirow{2}{*}{$\begin{array}{l}\text { State the process for } \\
\text { selecting sources } \\
\text { of evidence (i.e., } \\
\text { screening, eligibility) } \\
\text { included in the } \\
\text { scoping review }\end{array}$} & \multirow[t]{2}{*}{$8-9$} & $\begin{array}{l}\text { Critical appraisal } \\
\text { within sources of } \\
\text { evidence }\end{array}$ & 19 & $\begin{array}{l}\text { If done, present data } \\
\text { on critical appraisal } \\
\text { of included sources } \\
\text { of evidence (see } \\
\text { item 12) }\end{array}$ & NA \\
\hline & & & & $\begin{array}{l}\text { Results of individual } \\
\text { sources of evi- }\end{array}$ & 20 & $\begin{array}{l}\text { For each included } \\
\text { source of evidence, }\end{array}$ & $11,14,17$ \\
\hline \multirow[t]{4}{*}{$\begin{array}{l}\text { Data charting } \\
\text { process }\end{array}$} & \multirow[t]{4}{*}{10} & \multirow{4}{*}{$\begin{array}{l}\text { Describe the methods } \\
\text { of charting data } \\
\text { from the included } \\
\text { sources of evidence } \\
\text { (e.g., piloted forms; } \\
\text { forms that have } \\
\text { been tested by the } \\
\text { team before their } \\
\text { use, whether data } \\
\text { charting was done } \\
\text { independently, in } \\
\text { duplicate) and any } \\
\text { processes for obtain- } \\
\text { ing and confirming } \\
\text { data from investiga- } \\
\text { tors }\end{array}$} & \multirow[t]{4}{*}{$8-9$} & dence & & $\begin{array}{l}\text { present the relevant } \\
\text { data that were } \\
\text { charted that relate } \\
\text { to the review } \\
\text { question(s) and } \\
\text { objective(s) }\end{array}$ & \\
\hline & & & & Synthesis of results & 21 & $\begin{array}{l}\text { Summarize and/or } \\
\text { present the chart- } \\
\text { ing results as they } \\
\text { relate to the review } \\
\text { question(s) and } \\
\text { objective(s) }\end{array}$ & $10-18$ \\
\hline & & & & $\begin{array}{l}\text { Risk of bias across } \\
\text { studies }\end{array}$ & 22 & $\begin{array}{l}\text { Not applicable for } \\
\text { scoping reviews }\end{array}$ & NA \\
\hline & & & & Additional analyses & 23 & Not applicable for & NA \\
\hline \multirow[t]{2}{*}{ Data items } & \multirow[t]{2}{*}{11} & \multirow{2}{*}{$\begin{array}{l}\text { List and define all vari- } \\
\text { ables for which data } \\
\text { were sought and any } \\
\text { assumptions and } \\
\text { simplifications made }\end{array}$} & \multirow[t]{2}{*}{$8-9$} & Discussion & & scoping reviews & \\
\hline & & & & $\begin{array}{l}\text { Summary of evi- } \\
\text { dence }\end{array}$ & 24 & $\begin{array}{l}\text { Summarize the main } \\
\text { results (including } \\
\text { an overview of }\end{array}$ & $19-23$ \\
\hline \multirow[t]{2}{*}{$\begin{array}{l}\text { Critical appraisal of } \\
\text { individual sources } \\
\text { of evidence }\end{array}$} & \multirow[t]{2}{*}{12} & \multirow[t]{2}{*}{$\begin{array}{l}\text { If done, provide } \\
\text { a rationale for } \\
\text { conducting a critical } \\
\text { appraisal of included } \\
\text { sources of evidence; } \\
\text { describe the meth- } \\
\text { ods used and how } \\
\text { this information was } \\
\text { used in any data syn- } \\
\text { thesis (if appropriate) }\end{array}$} & \multirow[t]{2}{*}{ NA } & & & $\begin{array}{l}\text { concepts, themes, } \\
\text { and types of } \\
\text { evidence available), } \\
\text { explain how they } \\
\text { relate to the review } \\
\text { question(s) and } \\
\text { objectives, and con- } \\
\text { sider the relevance } \\
\text { to key groups }\end{array}$ & \\
\hline & & & & Limitations & 25 & Discuss the limitations & $23-25$ \\
\hline Summary measures & 13 & $\begin{array}{l}\text { Not applicable for } \\
\text { scoping reviews }\end{array}$ & NA & & & $\begin{array}{l}\text { of the scoping } \\
\text { review process }\end{array}$ & \\
\hline Synthesis of results & 14 & $\begin{array}{l}\text { Describe the methods } \\
\text { of handling and } \\
\text { summarizing the } \\
\text { data that were } \\
\text { charted }\end{array}$ & 9 & Conclusions & 26 & $\begin{array}{l}\text { Provide a general } \\
\text { interpretation of } \\
\text { the results with } \\
\text { respect to the } \\
\text { review question(s) }\end{array}$ & $25-26$ \\
\hline $\begin{array}{l}\text { Risk of bias across } \\
\text { studies }\end{array}$ & 15 & $\begin{array}{l}\text { Not applicable for } \\
\text { scoping reviews }\end{array}$ & NA & & & $\begin{array}{l}\text { and objective(s), } \\
\text { as well as potential }\end{array}$ & \\
\hline Additional analyses & 16 & $\begin{array}{l}\text { Not applicable for } \\
\text { scoping reviews }\end{array}$ & NA & & & $\begin{array}{l}\text { implications and/or } \\
\text { next steps }\end{array}$ & \\
\hline
\end{tabular}




\begin{tabular}{lll}
\hline Section & Item & $\begin{array}{l}\text { PRISMA-ScR checklist } \\
\text { item }\end{array}$ \\
\hline Funding & $27 \quad \begin{array}{l}\text { Reported on page \# } \\
\text { funding } \\
\text { funding for the of } \\
\text { included sources of } \\
\text { evidence, as well as } \\
\text { sources of funding } \\
\text { for the scoping } \\
\text { review. Describe the } \\
\text { role of the funders of } \\
\text { the scoping review }\end{array}$ \\
\hline
\end{tabular}

\section{Appendix 3: Key excluded sources with rationale for their exclusion}

\begin{tabular}{ll}
\hline References & Rationale for exclusion \\
\hline Slater et al. [81] & $\begin{array}{c}\text { Study did not attempt to draw a } \\
\text { relationship between HL and } \\
\text { LBP health outcomes }\end{array}$ \\
Larsen et al. [82] & Lack of significant LBP population \\
Khoshnevisan et al. [83] & Lack of explicit study of HL \\
Kim [84] & Lack of significant LBP population \\
Roth et al. [85] & Lack of explicit study of HL \\
Lardie et al. [86] & Lack of significant LBP population \\
Schulz et al. [87] & Lack of significant LBP population \\
Rabenbauer and Mevenkamp [88] & Lack of explicit study of HL \\
& Study did not attempt to draw a \\
& relationship between HL and \\
& LBP health outcomes \\
\hline
\end{tabular}

\section{Abbreviations}

HL: Health literacy; LBP: Low back pain; COS: Core Outcome Set; S-TOFHLA: Short-form Test of Functional Health Literacy in Adults; HeLMS: Health Literacy Measurement Scale; NVS: Newest Vital Sign; FABQ: Fear Avoidance Beliefs Questionnaire.

\section{Acknowledgements}

The authors wish to thank Dr. Jonathan Hill, Keele University, UK, for his comments on the initial draft of this manuscript.

\section{Authors' contributions}

CS provided review on titles and abstracts, full-text reviews of the shortlisted papers, and was a major contributor in writing the manuscript; BB and HES were involved in project conception, analysis and manuscript writing; LTC contributed to analysis and manuscript writing. JP contributed to manuscript writing and acted as the field expert in the consultation process. WWC collected the raw data, provided review on titles and abstracts, and full-text reviews of the shortlisted papers, and contributed to manuscript writing. All authors read and approved the final manuscript.

\section{Funding}

Not applicable.

\section{Availability of data and materials}

The datasets used and/or analysed during the current study are available from the corresponding author on reasonable request.

\section{Declarations}

Ethics approval and consent to participate Not applicable.

\section{Consent to publish}

Not applicable.

\section{Competing interests}

The authors declare that they have no competing interests.

\section{Author details}

${ }^{1}$ Lee Kong Chian School of Medicine, Nanyang Technological University, Singapore, Singapore. ${ }^{2}$ School of Primary, Community and Social Care, Keele University, Newcastle, UK.

Received: 23 March 2021 Accepted: 7 July 2021

Published online: 13 July 2021

\section{References}

1. World Health Organization. Musculoskeletal conditions. 2019 [cited 2019 Sep 12]. Available from https://www.who.int/news-room/fact-sheets/ detail/musculoskeletal-conditions.

2. Freburger JK, Holmes GM, Agans RP, Jackman AM, Darter JD, Wallace AS, et al. The rising prevalence of chronic low back pain. Arch Intern Med. 2009;169(3):251-8.

3. Wu A, March L, Zheng X, Huang J, Wang X, Zhao J, et al. Global low back pain prevalence and years lived with disability from 1990 to 2017: estimates from the Global Burden of Disease Study 2017. Ann Transl Med. 2020 Mar [cited 2021 Apr 30];8(6). Available from https://www.ncbi.nlm. nih.gov/pmc/articles/PMC7186678/.

4. Manchikanti L, Singh V, Falco FJE, Benyamin RM, Hirsch JA. Epidemiology of low back pain in adults. Neuromodulation J Int Neuromodulation Soc. 2014;17(Suppl 2):3-10.

5. Ricci JA, Stewart WF, Chee E, Leotta C, Foley K, Hochberg MC. Back pain exacerbations and lost productive time costs in United States workers. Spine. 2006;31 (26):3052-60.

6. Marin TJ, Van Eerd D, Irvin E, Couban R, Koes BW, Malmivaara A, et al. Multidisciplinary biopsychosocial rehabilitation for subacute low back pain. Cochrane Database Syst Rev. 2017 Jun 28 [cited 2019 Sep 10];2017(6). Available from https://www.ncbi.nlm.nih.gov/pmc/articles/PMC64 81490/.

7. Hayden JA, Chou R, Hogg-Johnson S, Bombardier C. Systematic reviews of low back pain prognosis had variable methods and results: guidance for future prognosis reviews. J Clin Epidemiol. 2009;62(8):781-796.e1.

8. Karran EL, Grant AR, Moseley GL. Low back pain and the social determinants of health: a systematic review and narrative synthesis. Pain. 2020;161(11):2476-93.

9. Bair MJ, Matthias MS, Nyland KA, Huffman MA, Stubbs DWL, Kroenke K, et al. Barriers and facilitators to chronic pain self-management: a qualitative study of primary care patients with comorbid musculoskeletal pain and depression. Pain Med. 2009;10(7):1280-90.

10. Briggs AM, Jordan JE, Buchbinder R, Burnett AF, O'Sullivan PB, Chua JYY, et al. Health literacy and beliefs among a community cohort with and without chronic low back pain. Pain. 2010;150(2):275-83.

11. Farin $E, U$ Ullrich $A$, Nagl M. Health education literacy in patients with chronic musculoskeletal diseases: development of a new questionnaire and sociodemographic predictors. Health Educ Res. 2013;28(6):1080-91.

12. Devraj R, Herndon CM, Griffin J. Pain awareness and medication knowledge: a health literacy evaluation. J Pain Palliat Care Pharmacother. 2013;27(1):19-27.

13. Baker DW. The meaning and the measure of health literacy. J Gen Intern Med. 2006;21(8):878-83.

14. Health promotion glossary. [Cited 2020 Jun 20]. Available from https:// www.who.int/publications-detail-redirect/health-promotion-glossary.

15. Health ND, Glossary P. Health Promot Int. 1998;13(4):349-64.

16. Buchbinder R, Batterham R, Ciciriello S, Newman S, Horgan B, Ueffing E, et al. Health literacy: what is it and why is it important to measure? J Rheumatol. 2011;38(8):1791-7.

17. Baker DW, Wolf MS, Feinglass J, Thompson JA, Gazmararian JA, Huang J. Health literacy and mortality among elderly persons. Arch Intern Med. 2007;167(14):1503-9. 
18. Dewalt DA, Berkman ND, Sheridan S, Lohr KN, Pignone MP. Literacy and health outcomes: a systematic review of the literature. J Gen Intern Med. 2004;19(12):1228-39.

19. Berkman ND, Sheridan SL, Donahue KE, Halpern DJ, Crotty K. Low health literacy and health outcomes: an updated systematic review. Ann Intern Med. 2011;155(2):97-107.

20. Köppen PJ, Dorner TE, Stein KV, Simon J, Crevenna R. Health literacy, pain intensity and pain perception in patients with chronic pain. Wien Klin Wochenschr. 2018;130(1-2):23-30.

21. Chiarotto A, Terwee CB, Deyo RA, Boers M, Lin C-WC, Buchbinder R, et al. A core outcome set for clinical trials on non-specific low back pain: study protocol for the development of a core domain set. Trials. 2014;15:511.

22. Chiarotto A, Deyo RA, Terwee CB, Boers M, Buchbinder R, Corbin TP, et al. Core outcome domains for clinical trials in non-specific low back pain. Eur Spine J Off Publ Eur Spine Soc Eur Spinal Deform Soc Eur Sect Cerv Spine Res Soc. 2015;24(6):1127-42.

23. Stewart Williams J, Ng N, Peltzer K, Yawson A, Biritwum R, Maximova T, et al. Risk factors and disability associated with low back pain in older adults in low- and middle-income countries. Results from the WHO Study on Global AGEing and Adult Health (SAGE). PLoS ONE. 2015 Jun 4 [cited 2020 Feb 8];10(6). Available from https://www.ncbi.nlm.nih.gov/pmc/ articles/PMC4456393/.

24. Volinn E. The epidemiology of low back pain in the rest of the world. A review of surveys in low- and middle-income countries. Spine. 1997;22(15):1747-54.

25. Driscoll T, Jacklyn G, Orchard J, Passmore E, Vos T, Freedman G, et al. The global burden of occupationally related low back pain: estimates from the Global Burden of Disease 2010 study. Ann Rheum Dis. 2014;73(6):975-81.

26. Yeo SN, Tay KH. Pain prevalence in Singapore. Ann Acad Med Singapore. 2009;38(11):937-42.

27. Edward J, Carreon LY, Williams MV, Glassman S, Li J. The importance and impact of patients' health literacy on low back pain management: a systematic review of literature. Spine J Off J North Am Spine Soc. 2018:18(2):370-6.

28. Munn Z, Peters MDJ, Stern C, Tufanaru C, McArthur A, Aromataris E. Systematic review or scoping review? Guidance for authors when choosing between a systematic or scoping review approach. BMC Med Res Methodol. 2018;18(1):143.

29. Arksey H, O'Malley L. Scoping studies: towards a methodological framework. Int J Soc Res Methodol Theory Pract. 2005;8(1):19-32.

30. Peters M, Godfrey C, Mclnerney P, Soares CB, Khalil H, Parker D. Methodology for JBI scoping reviews. 2015;3-24.

31. Deanna LO. The impact of patient education on disease outcomes. Available from http://rheumatologypracticemanagement.com/rpm-issues/ 2014/august-2014-vol-2-no-4/2347-the-impact-of-patient-education-ondisease-outcomes.

32. Tricco AC, Lillie E, Zarin W, O'Brien KK, Colquhoun H, Levac D, et al. PRISMA extension for scoping reviews (PRISMA-SCR): checklist and explanation. Ann Intern Med. 2018;169(7):467-73.

33. Sun $X$, Shi $Y$, Zeng $Q$, Wang $Y$, Du W, Wei N, et al. Determinants of health literacy and health behavior regarding infectious respiratory diseases: a pathway model. BMC Public Health. 2013;13(1):1-8.

34. Levac D, Colquhoun $\mathrm{H}, \mathrm{O}^{\prime}$ Brien KK. Scoping studies: advancing the methodology. Implement Sci. 2010;5(1):69.

35. Ritchie J, Spencer L. Chapter 9: Qualitative data analysis for applied policy research. In: Burgess RG, Bryman A, editors. Analyzing qualitative data. London; New York: Routledge; 1994 [cited 2020 Feb 8]. p. 173-94. Available from http://ezproxy.library.uq.edu.au/login?url=http://search. ebscohost.com/login.aspx?direct=true $\& \mathrm{db}=$ nlebk\&AN=72371\&site $=$ ehost-live.

36. Gale NK, Heath G, Cameron E, Rashid S, Redwood S. Using the framework method for the analysis of qualitative data in multi-disciplinary health research. BMC Med Res Methodol. 2013;18(13):117.

37. Nutbeam D. Health literacy as a public health goal: a challenge for contemporary health education and communication strategies into the $21 \mathrm{st}$ century. Health Promot Int. 2000;15(3):259-67.

38. Sykes S, Wills J, Rowlands G, Popple K. Understanding critical health literacy: a concept analysis. BMC Public Health. 2013;13(1):1-10.
39. NHS The Health Literacy Place / Teach back. [cited 2021 May 26]. Available from http://www.healthliteracyplace.org.uk/tools-and-techniques/techn iques/teach-back/.

40. de Wit L, Fenenga C, Giammarchi C, di Furia L, Hutter I, de Winter A, et al. Community-based initiatives improving critical health literacy: a systematic review and meta-synthesis of qualitative evidence. BMC Public Health. 2017;18(1):40.

41. Briggs AM, Jordan JE, O'Sullivan PB, Buchbinder R, Burnett AF, Osborne $\mathrm{RH}$, et al. Individuals with chronic low back pain have greater difficulty in engaging in positive lifestyle behaviours than those without back pain: an assessment of health literacy. BMC Musculoskelet Disord. 2011:12:161-161

42. Collins SA, Currie LM, Bakken S, Vawdrey DK, Stone PW. Health literacy screening instruments for eHealth applications: a systematic review. J Biomed Inform. 2012;45(3):598-607.

43. Baker DW, Williams MV, Parker RM, Gazmararian JA, Nurss J. Development of a brief test to measure functional health literacy. Patient Educ Couns. 1999:38(1):33-42

44. Jordan JE, Buchbinder R, Briggs AM, Elsworth GR, Busija L, Batterham R, et al. The Health Literacy Management Scale (HeLMS): a measure of an individual's capacity to seek, understand and use health information within the healthcare setting. Patient Educ Couns. 2013;91(2):228-35.

45. Jordan JE. Conceptualising and measuring health literacy from the patient perspective. 2009 [cited 2021 May 3]; Available from http://miner va-access.unimelb.edu.au/handle/11343/35275.

46. Jordan JE, Buchbinder R, Osborne RH, Barber MN, Staples M, Clerehan $R$, et al. The Health Literacy Management Scale (HeLMS): a measure of an individual's capacity to seek, understand and use health information within the healthcare setting. Patient Educ Couns. 2010;24:36-42.

47. Glassman SD, Carreon LY, Brown ME, Jones JS, Edward J, Li J, et al. The impact of health literacy on health status and resource utilization in lumbar degenerative disease. Spine J Off J North Am Spine Soc. 2019;19(4):711-6.

48. Al-Eisa E, Buragadda S, Melam G. Health literacy and fear avoidance beliefs among women with chronic low back pain. Phys Med Rehabil Kurortmed. 2017;27(2):95-9.

49. Weiss BD, Mays MZ, Martz W, Castro KM, DeWalt DA, Pignone MP, et al. Quick assessment of literacy in primary care: the newest vital sign. Ann Fam Med. 2005;3(6):514-22.

50. Shah LC, West P, Bremmeyr K, Savoy-Moore RT. Health literacy instrument in family medicine: the 'newest vital sign' ease of use and correlates. J Am Board Fam Med JABFM. 2010:23(2):195-203.

51. Camerini AL, Schulz PJ. Health literacy and patient empowerment: separating con-joined twins in the context of chronic low back pain. PLoS ONE. 2015;10(2):e0118032.

52. Maciel SC, Jennings F, Jones A, Natour J. The development and validation of a low back pain knowledge questionnaire-LKQ. Clinics. 2009;64(12):1167-75.

53. Burke A, Nahin RL, Stussman BJ. Limited health knowledge as a reason for non-use of four common complementary health practices. PLOS ONE. 2015;10(6):e0129336.

54. MacLeod S, Musich S, Gulyas S, Cheng Y, Tkatch R, Cempellin D, et al. The impact of inadequate health literacy on patient satisfaction, healthcare utilization, and expenditures among older adults. Geriatr Nurs NY N. 2017;38(4):334-41.

55. Wallace LS, Rogers ES, Roskos SE, Holiday DB, Weiss BD. BRIEF REPORT: screening items to identify patients with limited health literacy skills. J Gen Intern Med. 2006;21(8):874-7.

56. Chew LD, Bradley KA, Boyko EJ. Brief questions to identify patients with inadequate health literacy. Fam Med. 2004;36(8):588-94.

57. Hahn EA, Choi SW, Griffith JW, Yost KJ, Baker DW. Health literacy assessment using talking touchscreen technology (Health LiTT): a new item response theory-based measure of health literacy. J Health Commun. 2011;16(Suppl 3):150-62.

58. Melzack R. The short-form McGill pain questionnaire. Pain. 1987:30(2):191-7.

59. Fairbank JC, Pynsent PB. The Oswestry Disability Index. Spine. 2000:25(22):2940-52 (discussion 2952).

60. Waddell G, Newton M, Henderson I, Somerville D, Main CJ. A Fear-Avoidance Beliefs Questionnaire (FABQ) and the role of fear-avoidance beliefs in chronic low back pain and disability. Pain. 1993;52(2):157-68. 
61. Symonds TL, Burton AK, Tillotson KM, Main CJ. Do attitudes and beliefs influence work loss due to low back trouble? Occup Med Oxf Engl. 1996;46(1):25-32.

62. Speros C. Health literacy: concept analysis. J Adv Nurs. 2005;50(6):633-40.

63. Dieleman $J$, Baral R, Birger M, Bui AL, Bulchis A, Chapin A, et al. US spending on personal health care and public health, 1996-2013. JAMA. 2016;316(24):2627-46.

64. World Bank. World Bank Country and Lending Groups. [cited 2021 May 2]. Available from https://datahelpdesk.worldbank.org/knowledgebase/artic les/906519.

65. Culture \& Health Literacy | Health Literacy | CDC. 2019 [cited 2020 Jan 15]. Available from https://www.cdc.gov/healthliteracy/culture.html.

66. Chiarotto A, Boers M, Deyo RA, Buchbinder R, Corbin TP, Costa LOP, et al. Core outcome measurement instruments for clinical trials in nonspecific low back pain. Pain. 2018;159(3):481-95.

67. Creswell J, Clark V. Designing and conducting mixed methods research. Thousand Oaks: SAGE; 2018.

68. Kingsley C, Patel S. Patient-reported outcome measures and patientreported experience measures. BJA Educ. 2017;17(4):137-44.

69. Tidstrand J, Horneij E. Inter-rater reliability of three standardized functional tests in patients with low back pain. BMC Musculoskelet Disord. 2009;2(10):58.

70. Apkarian AV, Krauss BR, Fredrickson BE, Szeverenyi NM. Imaging the pain of low back pain: functional magnetic resonance imaging in combination with monitoring subjective pain perception allows the study of clinical pain states. Neurosci Lett. 2001;299(1):57-60

71. Bartlam B, Crome P, Lally F, Beswick AD, Cherubini A, Clarfield AM, et al. The views of older people and carers on participation in clinical trials: the PREDICT Study. Clin Investig. 2012;2(3):327-36.

72. Nguyen TH, Park H, Han H-R, Chan KS, Paasche-Orlow MK, Haun J, et al. State of the science of health literacy measures: validity implications for minority populations. Patient Educ Couns. 2015;98:1492-512.

73. Melinda Y. Low Health Literacy Is Major Barrier to Research Participation. 2019. Available from https://www.reliasmedia.com/articles/143911-lowhealth-literacy-is-major-barrier-to-research-participation.

74. Institute of Medicine (US) Committee on Standards for Systematic Reviews of Comparative Effectiveness Research. Finding what works in health care: standards for systematic reviews. Eden J, Levit L, Berg A, Morton S, editors. Washington (DC): National Academies Press (US); 2011 [cited 2021 May 5]. Available from http://www.ncbi.nlm.nih.gov/books/ NBK209518/.

75. Paez A. Gray literature: an important resource in systematic reviews. J Evid Based Med. 2017;10(3):233-40.

76. Lawitz E, Sulkowski MS, Ghalib R, Rodriguez-Torres M, Younossi ZM, Corregidor A, et al. Simeprevir plus sofosbuvir, with or without ribavirin, to treat chronic infection with hepatitis $C$ virus genotype
1 in non-responders to pegylated interferon and ribavirin and treatment-naive patients: the COSMOS randomised study. Lancet. 2014;384(9956):1756-65.

77. Emelifeonwu JA, Flower H, Loan JJ, McGivern K, Andrews PJD. Prevalence of anterior pituitary dysfunction 12 months or more following traumatic brain injury in adults: a systematic review and meta-analysis. J Neurotrauma. 2019:37(2):217-26.

78. Skovlund PC, Nielsen BK, Thaysen HV, Schmidt H, Finset A, Hansen KA, et al. The impact of patient involvement in research: a case study of the planning, conduct and dissemination of a clinical, controlled trial. Res Involv Engag. 2020;6(1):43.

79. Puerta LL, Bartlam B, Smith HE. Researchers' perspectives on public involvement in health research in Singapore: the argument for a community-based approach. Health Expect. 2019;22(4):666-75.

80. Puerta LL, Bartlam B, Sun H-LS, Smith HE. Perspectives on public involvement in health research from Singapore: the potential of a supported group model of involvement. Health Expect. 2020;23(5):1074-85.

81. Slater H, Briggs AM, Bunzli S, Davies SJ, Smith AJ, Quintner JL. Engaging consumers living in remote areas of Western Australia in the self-management of back pain: a prospective cohort study. BMC Musculoskelet Disord. 2012;13(1):69.

82. Larsen AK, Holtermann A, Mortensen OS, Punnett L, Rod MH, Jørgensen MB. Organizing workplace health literacy to reduce musculoskeletal pain and consequences. BMC Nurs. 2015;14(1):46.

83. Khoshnevisan A, Yekaninejad MS, Pakpour AHA, Mardani A. Misunderstanding prescription physician's oral instructions in patients with low back pain. Acta Med Iran. 2010;48(6):407-11.

84. Kim SH. Health literacy and functional health status in Korean older adults. J Clin Nurs. 2009;18(16):2337-43.

85. Roth RS, Punch MR, Bachman JE. Educational achievement and pain disability among women with chronic pelvic pain. J Psychosom Res. 2001;51(4):563-9.

86. Hardie NA, Kyanko K, Busch S, LoSasso AT, Levin RA. Health literacy and health care spending and utilization in a consumer-driven health plan. J Health Commun. 2011;16(sup3):308-21.

87. Schulz PJ, Rubinelli S, Zufferey MC, Hartung U. Coping with chronic lower back pain: designing and testing the online tool ONESELF. J Comput Mediat Commun. 2010;15(4):625-45.

88. Rabenbauer LM, Mevenkamp N. Factors in the effectiveness of e-health interventions for chronic back pain: how self-efficacy mediates e-health literacy and healthy habits. Telemed E-Health. 2020;27(2):184-92.

\section{Publisher's Note}

Springer Nature remains neutral with regard to jurisdictional claims in published maps and institutional affiliations.
Ready to submit your research? Choose BMC and benefit from:

- fast, convenient online submission

- thorough peer review by experienced researchers in your field

- rapid publication on acceptance

- support for research data, including large and complex data types

- gold Open Access which fosters wider collaboration and increased citations

- maximum visibility for your research: over $100 \mathrm{M}$ website views per year

At BMC, research is always in progress.

Learn more biomedcentral.com/submissions 